\title{
Operational Ozone Forecasts for Austria
}

\author{
Marcus Hirtl ${ }^{1}$, Kathrin Baumann-Stanzer ${ }^{1}$ and Bernd C. Krüger ${ }^{2}$ \\ ${ }^{1}$ Central Institute for Meteorology and Geodynamics (ZAMG), Vienna, Austria \\ ${ }^{2}$ Institute of Meteorology, Department Water, Atmosphere, and Environment, \\ University of Natural Resources and Applied Life Sciences Vienna (BOKU), Austria
}

\section{INTRODUCTION}

Daily ozone-forecasts for Austria have been run in a operational mode during summer 2005 and 2006.

The model system has been set up for Austria in cooperation of the Central Institute for Meteorology and Geodynamic and the University of Natural Resources and Applied Life Sciences. The meteorological fields are supplied by the limited area model ALADIN-Austria (run twice a day at ZAMG). 48-hours forecasts are computed with a horizontal resolution of $9.6 \mathrm{~km}$ covering Austria and $29 \mathrm{~km}$ for Central Europe. The dispersion modelling is done with the Comprehensive Air quality Model CAMx (version 4.20) with the SAPRC99mechanism for gas phase chemistry.

\section{DESCRIPTION OF THE MODELLING SYSTEM}

The new air quality model system consists of three parts that are linked together. The combination of the two major parts, the meteorological input provided by ALADIN and the chemical model CAMx, was implemented for the first time in this study.

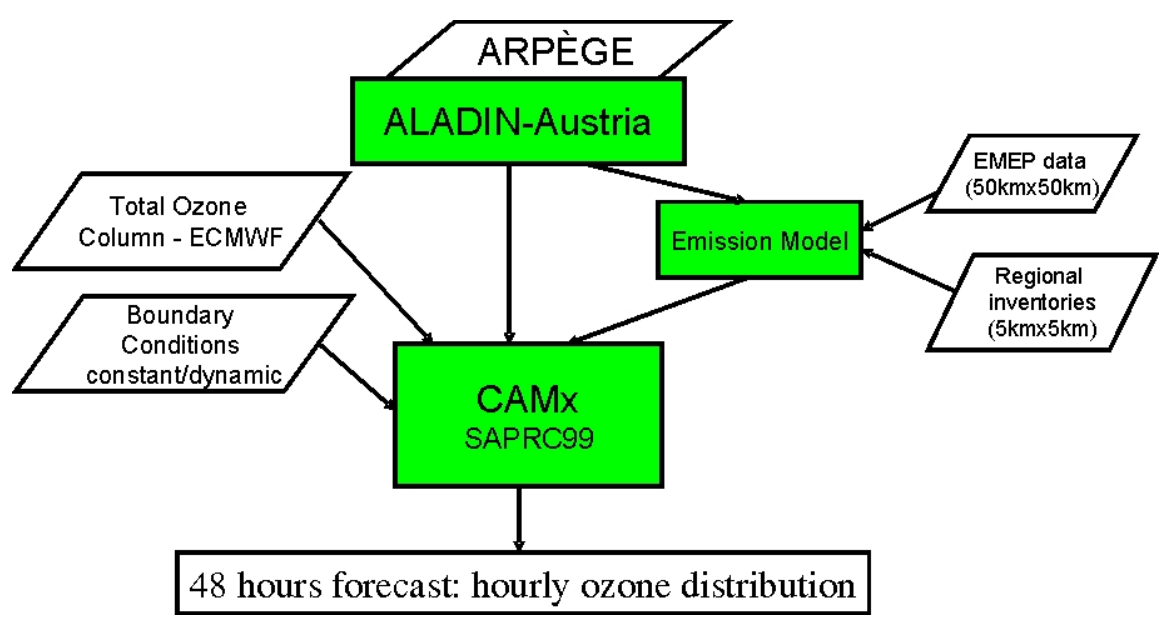

CAMx (Comprehensive Air qualtity Model with extensions, http://www.camx.com) simulates the emission, dispersion, chemical reaction, and removal of pollutants in the troposphere by solving the pollutant continuity equation for each chemical species on a system of nested 3D grids. A two grid nesting is used with a coarse grid over Europe and a finer grid for the core area covering Austria with the best possible spatial resolution of $9.6 \mathrm{~km}$ (according to the present grid of ALADIN-Austria).

The meteorological fields are supplied by the limited area model ALADIN-Austria (http://www.cnrm.meteo.fr/aladin/). It is run twice a day at the ZAMG and renders forecasts for 48 hours. The meteorological fields have a temporal resolution of one hour. The data is provided on 45 model-levels and has a horizontal resolution of $9.6 \mathrm{~km}$. Fields of wind, 
temperature, pressure, convective and large scale precipitation, snow cover, solar radiation and specific humidity are extracted directly out of the ALADIN dataset. The other fields, cloud optical depth, cloud water- and precipitation water content have to be parameterised (Seinfeld, 1998) from the ALADIN output.

The model system generally uses EMEP emissions. For the countries Austria, Czech Republic, Slovakia and Hungary, the original $50 \mathrm{~km}$ x $50 \mathrm{~km}$ data are downscaled to $5 \mathrm{~km} \times 5$ $\mathrm{km}$ based on an inventory from 1995 (Winiwarter and Zueger, 1996). The EMEP data for 1999 (used in the 2005 forecast) has been substituted by data for 2003 (Vestreng et al., 2005). In addition, a new highly resolved emission inventory for the City of Vienna (Orthofer et al., 2005) is used for this area.

The boundary conditions of the coarse grid were estimated from the forecast of the previous day. This method is compared with constant boundary conditions using average summer values. Total ozone column data was obtained from ECMWF data.

\section{OPERATIONAL FORECASTS 2006}

High ozone values are most frequently encountered in the eastern parts of Austria, where warnings for values above the information or the alarm threshold are launched for ozone region 1 (covering Lower Austria, Vienna and Burgenland).

Figure 1 shows the predicted maximum concentrations for ozone region 1 . The course of ozone concentration from one day (Tag 1) and two-days (Tag 2) model forecasts as well as the results from a backup run which considers constant boundary conditions only are compared to measurements (43 air quality stations).

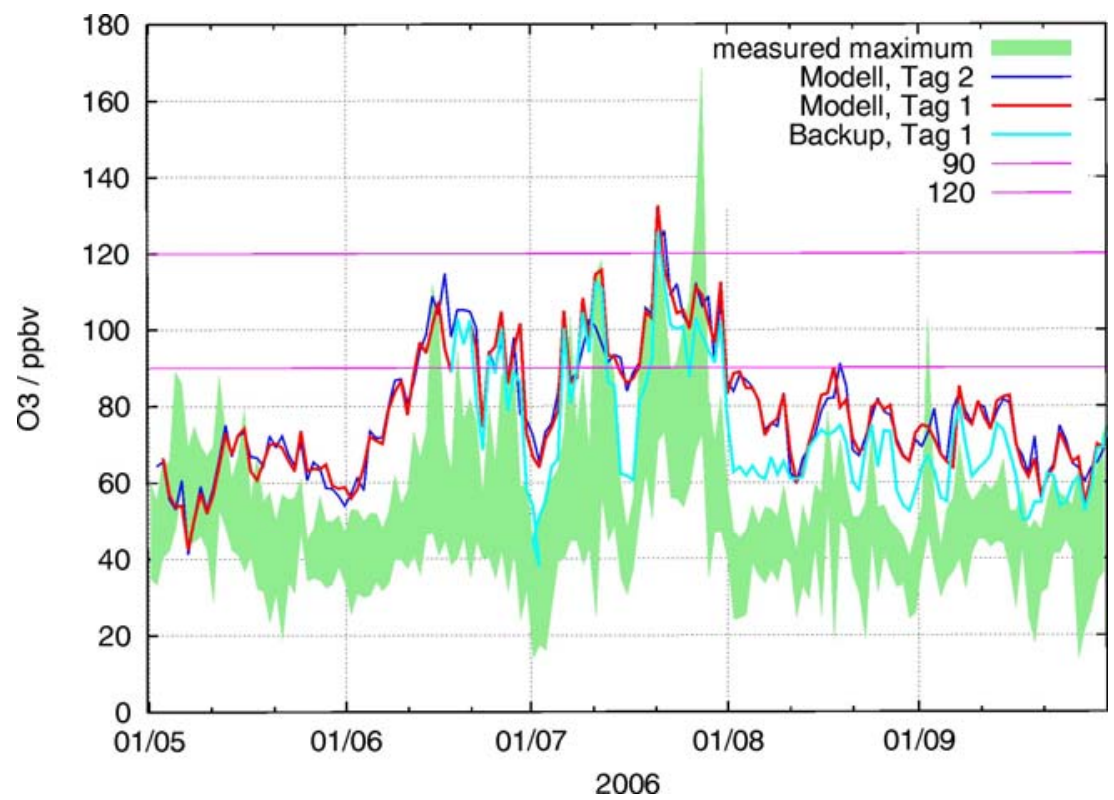

Fig. 1: Daily ozone maxima in the Austrian ozone region 1.

Green area: range between highest and lowest maximum observations (hourly average) at stations within the region

Blue line: maximum predicted on same day

Red line: maximum predicted on previous day

Yellow line: backup run (constant boundary conditions) 
Exceedances of the information threshold of $180 \mu \mathrm{g} / \mathrm{m} 3$ ( $90 \mathrm{ppbv}$ ) occured in 2006 between mid of June and end of July. After that period the predicted concentrations were higher than the measurements. The yellow line shows that the model run considering constant boundary conditions performs slightly better than the dynamic approach during that period.

According to the station measurements, the information threshold has been exceeded on 17 days in the period depicted in Fig. 1.16 of these exceedances were forecasted correctly. The alert exceedance predicted for July 21 was not observed but the measured values were just below the threshold value. The daily maxima above the alert threshold which were observed on July 27 and 28, 2006, were not predicted by the model. On these days, local peak emissions obviously caused a sudden and local increase of ozone concentrations around noon for one or two hours.

Figure 2 shows a scatter diagram of observed and modelled value pairs for ozone region 1. Depicted are daily maximum concentrations for the two forecast days and the backup run. Information and alarm threshold are marked by magenta lines. Most of the values lie above the 1:1 line which means that the model tends to predict higher concentrations than observed

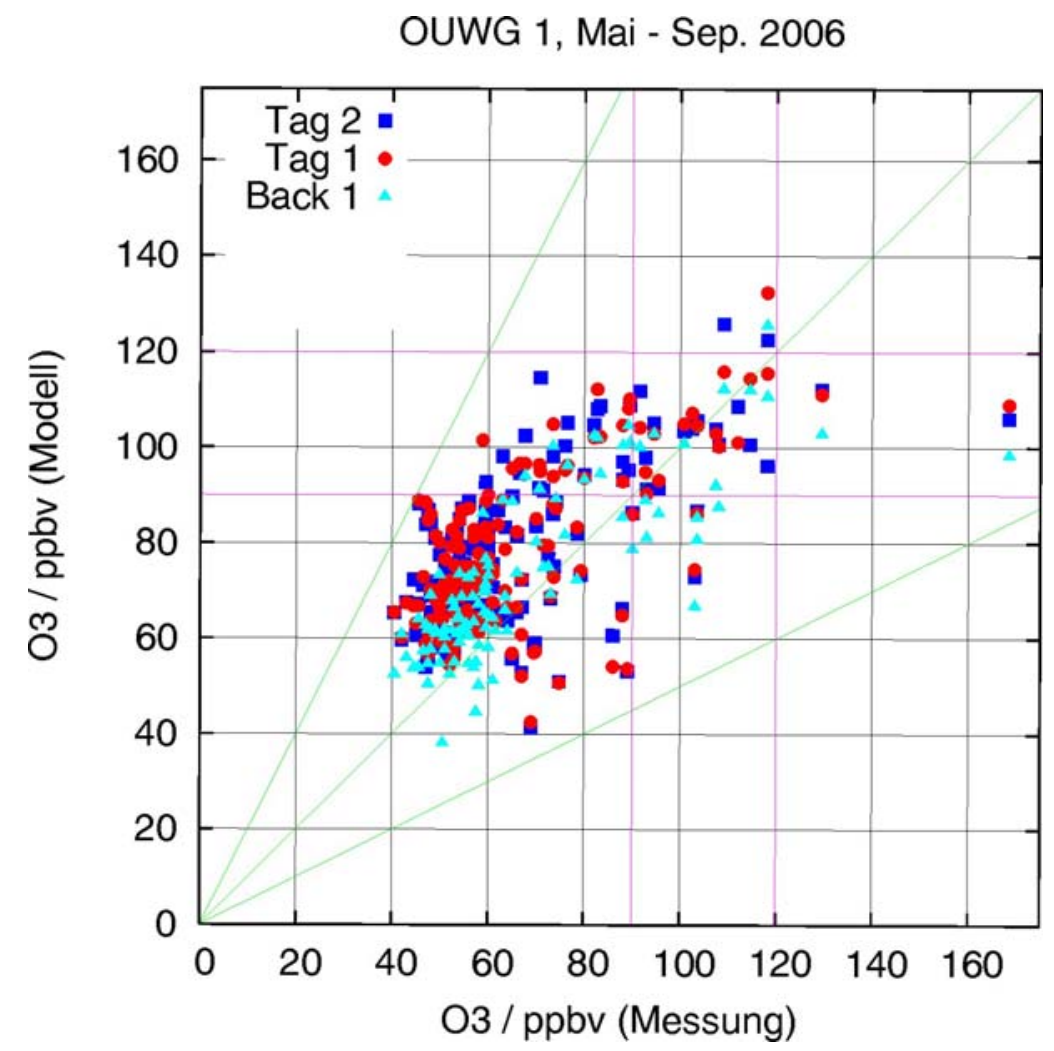

Fig. 2: Scatter-diagram of daily ozone maxima predicted versus observed in ozone region 1 for 2006.

Blue: maximum predicted on previous day

Red : maximum predicted on same day

Light blue: maximum predicted by back up run

Magenta lines: information and alert threshold (Directive 2002/3/EC)

Table 1 summarizes the metrics of some selected stations in ozone region 1 . The correlation and the standard deviation between observations and model prediction of the two forecast 
days as well as the backup run are depicted. The last line shows the values for all 43 stations in ozone region 1.

\begin{tabular}{|l|r|r|r|r|r|r|}
\hline & \multicolumn{2}{|c|}{ forecast day 1 } & \multicolumn{2}{r|}{ forecast day 2 } & \multicolumn{2}{r|}{ Backup day 1 } \\
\hline & $\mathrm{r}$ & $\mathrm{s}$ & $\mathrm{r}$ & $\mathrm{s}$ & $\mathrm{r}$ & $\mathrm{s}$ \\
\hline Eisenstadt & 0.62 & 12.16 & 0.61 & 12.54 & 0.73 & 10.26 \\
\hline Kittsee & 0.63 & 13.47 & 0.64 & $\mathbf{1 3 . 1 5}$ & 0.72 & 11.75 \\
\hline Himberg & $\mathbf{0 . 6 9}$ & 13.10 & 0.69 & $\mathbf{1 3 . 2 9}$ & 0.76 & 11.51 \\
\hline Schwechat & 0.71 & 13.85 & 0.71 & 13.99 & 0.78 & 12.10 \\
\hline Tulln & 0.65 & 14.27 & 0.65 & 13.84 & 0.70 & 12.49 \\
\hline Wiener Neustadt & 0.54 & 12.23 & 0.55 & $\mathbf{1 2 . 2 7}$ & 0.64 & 10.48 \\
\hline Hohe Warte & $\mathbf{0 . 6 8}$ & 13.33 & 0.68 & $\mathbf{1 3 . 5 3}$ & 0.75 & 11.56 \\
\hline Lobau & $\mathbf{0 . 7 1}$ & 13.71 & 0.71 & $\mathbf{1 3 . 9 9}$ & $\mathbf{0 . 7 8}$ & 12.03 \\
\hline Average & $\mathbf{0 . 5 9}$ & $\mathbf{1 3 . 0 3}$ & $\mathbf{0 . 5 9}$ & $\mathbf{1 3 . 0 0}$ & $\mathbf{0 . 7 0}$ & $\mathbf{1 0 . 9 3}$ \\
\hline
\end{tabular}

Table 1: correlation (r) and standard deviation (s) of selected stations in ozone region 1.

The correlation between the two forecast days with the measurements are practically the same. It seems that the backup run correlates better with the observations for the selected stations as well as for the whole ozone region 1 . The standard deviation is also smaller for the backup run.

The statistical comparisons between ozone forecasts and measurements for all stations in eastern Austria render correlation coefficients between 0.4 and 0.7 and standard errors around 12 ppbv for the year 2006.

It was investigated how accurate exceedances of the information threshold could be predicted by the model. The following combinations were considered:

Days when

- the highest value of the observations as well as the model forecasts are bellow the information threshold (90 ppbv) in ozone region 1

- observation and model lie above the threshold

- the observations lie below the threshold, the model above it

- the observations lie above the threshold, the model below it

Table 2 shows the values for the respective months. Operational forecasts of 2006 and 2005 are compared to the results of the backup run. 


\begin{tabular}{|c|c|c|c|c|c|c|c|c|}
\hline Obs. & Mod. & May & June & July & Aug. & Sep. & Total & $\%$ \\
\hline \multicolumn{9}{|c|}{ Forecast 2006 , day 1} \\
\hline$<90$ & $<90$ & 28 & 16 & 11 & 31 & 30 & 116 & \multirow{2}{*}{88.0} \\
\hline$>90$ & $>90$ & 0 & 3 & 13 & 0 & 0 & 16 & \\
\hline$<90$ & $>90$ & 0 & 11 & 6 & 0 & 0 & 17 & \multirow{2}{*}{12.0} \\
\hline$>90$ & $<90$ & 0 & 0 & 1 & 0 & 0 & 1 & \\
\hline \multicolumn{2}{|l|}{ Total } & 28 & 30 & 31 & 31 & 30 & 150 & \\
\hline \multicolumn{9}{|c|}{ Backup-run 2006, day 1} \\
\hline$<90$ & $<90$ & - & 7 & 10 & 31 & 30 & 78 & \multirow{2}{*}{84.8} \\
\hline$>90$ & $>90$ & - & 1 & 10 & 0 & 0 & 11 & \\
\hline$<90$ & $>90$ & - & 4 & 7 & 0 & 0 & 11 & \multirow{2}{*}{15.2} \\
\hline$>90$ & $<90$ & - & 1 & 4 & 0 & 0 & 5 & \\
\hline \multicolumn{2}{|l|}{ total } & - & 13 & 31 & 31 & 30 & 105 & \\
\hline \multicolumn{9}{|c|}{ Forecast 2005 , day 1} \\
\hline$<90$ & $<90$ & - & 3 & 25 & 30 & 27 & 84 & \multirow{2}{*}{90.9} \\
\hline$>90$ & $>90$ & - & 2 & 4 & 0 & 0 & 6 & \\
\hline$<90$ & $>90$ & - & 2 & 0 & 1 & 2 & 6 & \multirow{2}{*}{9.1} \\
\hline$>90$ & $<90$ & - & 0 & 2 & 0 & 1 & 3 & \\
\hline \multicolumn{2}{|l|}{ Total } & - & 7 & 31 & 31 & 30 & 99 & \\
\hline
\end{tabular}

Table 2: Hit-rate for the exceedance of the information threshold

Although the predicted ozone values tend to be higher than the observations in 2006 the hit rate to predict the exceedance of the information threshold is $88 \%$. This is slightly better than the backup run in 2006 (84,8\%) and worse than in 2005 where the hit rate was 90,9\%.

These values include also months with low ozone values in Austria. During the months May, August and September no exceedances of the information threshold occured because of the meteorological conditions. Considering only the months June and July 2006 (61 days) the hit rate would be $70,5 \%$ for the operational run and 63,6\% for the backup run.

\section{CONCLUSION}

Daily ozone forecasts for Austria have been run during summer 2005 and 2006. The results of the forecasts have been evaluated with measurements of the Austrian air quality network for eastern parts of Austria.

Generally the observed exceedances of the information threshold are reproduced by the model. Days with exceedances of the information threshold could be predicted by the model with a probability of $88 \%$ during the summer period in 2006. The daily maxima above the alert threshold were not predicted by the model mainly due to the rather low resolution.

The ozone forecasts are continued with an improved model system in the ozone season 2007. The emission inventories as well as the CAMx model will be updated. Additionally a new approach to obtain the boundary conditions from climatological average values will be applied and test runs with increased spatial resolution wil be conducted.

\section{ACKNOLEDGEMENTS}

This work has been founded by the Bundesministerium für Land- und Forstwirtschaft, Umwelt und Wasserwirtschaft (BMLFUW), by the Magistrat der Stadt Wien, by the Amt der Niederösterreichischen Landesregierung, the Amt der Burgenländischen Landesregierung, by the Amt der Steiermärkischen Landeregierung, by the Amt der Kärntner Landesregierung, by 
the Amt der Oberösterreichischen Landesregierung, and by the Amt der Salzburger Landesregierung.

\section{REFERENCES}

Gidhagen L. et al. (2004): Simulation of $\mathrm{NO}_{\mathrm{x}}$ and ultrafine particles in a street canyon in Stockholm, Sweden, Atmospheric Environment

Orthofer, R., H. Humer, W. Winiwarter, P. Kutschera, W. Loibl, T. Strasser, und J. PetersAnders, 2005: emikat.at - Emissionsdatenmanagement für die Stadt Wien. ARC system research, Bericht ARC-sys-0049, Seibersdorf, Austria, April 2005.

Seinfeld, J.H. and S.N. Pandis (1998): Atmospheric Chemistry and Physics, From Air Pollution to Climate Change (1173-1174), John Wiley and Sons, Inc, NY.

Vestreng, V. , et. al. (2004), Inventory Review 2004, Emission Data reported to CLRTAP and under the NEC Directive, EMEP/EEA Joint Review Report, EMEP/MSC-W Note 1/2004. ISSN 0804-2446.

Winiwarter, W. and J. Zueger, 1996: Pannonisches Ozonprojekt, Teilprojekt Emissionen. Endbericht. Report OEFZS-A-3817, Austrian Research Center, Seibersdorf. 